\title{
SOBRE LA OBRA FUNDAMENTAL DE DESCARTES'
}

Rafael Gonzalo Angarita Cáceres ${ }^{2}$

Universidad Industrial de Santander - Bucaramanga

\section{Resumen}

El artículo pretende mostrar, a la luz de un análisis textual, que la obra fundamental de Descartes es el diálogo, La Búsqueda de la Verdad Mediante la Luz Natural, en la medida en que tanto la forma (la conversación) como el contenido (el método y sus implicaciones) de este texto resultan cruciales para cumplir a cabalidad con el gran propósito de la reflexión cartesiana.

\section{Palabras clave}

Conversación, Descartes, Método y Verdad.

\section{ON PRINCIPAL BOOK BY DESGARTES}

\section{Ahstract}

This article tries to show, through a textual analysis that the fundamental work of Descartes is the dialogue's Search of Truth By Means of the Natural Light, therefore (the conversation) and content (the method and its implications) of the text are crucial to achieve completely with the great purpose of Cartesian thinking.

\section{Kev words}

Conversation, Descartes, Method and Truth.

1 El presente artículo de revisión se deriva de la tesis de Maestría, en la que se estudió la consideración de la historia en la filosofía de Descartes.

2 Filósofo UIS (2007), Magíster en Filosofía UIS (2010), Profesor Auxiliar, Universidad Industrial de Santander (UIS), Escuela de Filosofía. gonzoangarita@gmail.com 


\section{Introducción}

Cuando en filosofía se habla de diálogo inmediatamente las miradas se dirigen a Platón. Pero cuando se indica que Descartes posee un texto compuesto en esta forma literaria, se llega hacia dos circunstancias completamente contrarias. En primer lugar, una sorpresa que se expresa en la pregunta: ¿Hay diálogo cartesiano? En segundo lugar, quienes saben de la existencia del diálogo indican que lo realizado por Descartes corresponde a un texto didáctico que se ocupa en repetir formulaciones, metáforas y tesis del conjunto de la obra cartesiana y, especialmente, de las Meditaciones.

Justo aquí el lector se enfrenta con una disyuntiva: ¿Literatura o filosofía? Los partidarios de la primera opción se apoyarían en el género del texto, el diálogo, la creación de los personajes, sus locuciones y la distancia que toma el escritor frente al drama. Desde aquí, la posición literaria quedaría absolutamente justificada y el diálogo se instalaría en el reino de lo posible, en el ámbito de lo verosímil y, por ello mismo, hablaríamos de un Descartes literato. Pero tanto la filosofía cartesiana como el contenido específico del diálogo se resistirían a estas conclusiones y ello por dos razones esenciales. En primer lugar, porque este diálogo se distingue sustancialmente de todo diálogo, incluso del diálogo platónico, que desde la perspectiva cartesiana es abiertamente literario o perteneciente, más bien, a la historia de la literatura, toda vez que sólo se complace con tergiversar las enseñanzas de Sócrates, para hacer patente, luego de un recorrido más o menos amplio, que no se ha llegado a ningún fundamento que ostente la categoría de certeza, contrariamente a como sucede en la obra cartesiana, donde la certeza fundamentada constituye su propósito y conclusión (Cf., Descartes, 1989, p. 15).

En segundo lugar, porque la literatura, al igual que la propuesta aristotélica, perte- nece a ese gran cúmulo teórico “[...] que conduce a la vanidad de inventar intrincadas razones para expresar lo verosímil como verdadero [...]" (Descartes, 1981, AT, VI, p. 10). Con todo, se hace necesario afirmar que este Descartes literario o cercano a la literatura no es exclusivo del diálogo referido. Hay, por lo menos, otros dos lugares del último Descartes ${ }^{1}$ en que pueden observarse procedimientos expresamente literarios. El primero de ellos corresponde a los Principia. En el prefacio a este texto, Descartes (1989) indica a sus lectores que la obra presentada debe ser leída como una novela ( $p$. 20). Pues bien: ¿Por qué el filósofo que está preocupado por el establecimiento de la verdad, en el marco de un contexto eminentemente filosófico $y$, por ello mismo, científico, pide a sus lectores que lean un texto filosófico como si se tratase de una pieza literaria, en este caso, de una novela? ¿No conduciría tal procedimiento a que la argumentación incursionase en un sendero puramente ficcional, es decir, en lo verosímil, en suma, en todo lo contrario a su propuesta filosófica? Sobre esta cuestión, Turró afirma que los motivos de la afirmación cartesiana son, fundamentalmente, los siguientes. En primer lugar, ello obedece, dice, al hecho de que los Principia se postulan como un libro de carácter escolar. En segundo lugar, asevera, que lo consignado allí pretende presentar al mecanicismo como la descripción ontológicamente correcta del mundo (Cf., 1985, p. 39). No obstante, lo fuerte de las razones aducidas, la pregunta formulada parece seguir en pie: ¿Por qué leer un texto filosófico como si fuera una novela? Es decir, como si no fuese un texto filosófico.

Otro lugar en el que encontramos un procedimiento literario es en la organización general de lo narrado en el Discurso. En este texto, Descartes piensa y escribe desde un ejercicio narratológico donde la ficción toma, como es propio de toda elaboración de este tipo, su lugar corres- 
pondiente. Tal esfuerzo se constata en el carácter eminentemente autobiográfico que adquiere el Discurso, si bien algunos de sus pasajes no corresponde del todo a la vida de Descartes, sino que en muchos casos se eliminan ciertos compromisos asumidos, por ejemplo, con la episteme renacentista. Pero si profundizamos con más detalle en este texto, constataremos que Descartes se adhiere completamente al procedimiento literario con el objeto de escapar a cualquier condena posible por parte de la Iglesia. Así, por ejemplo, al iniciar la Quinta Parte afirma que no dirá cómo es el mundo, sino que, por el contrario, se limitará a decir cómo sería si Dios se decidiese a crearlo nuevamente (Cf., Descartes, 1981, AT, VI, p. 40 y ss.). Queda claro, que Descartes acude a lo ficcional como salvaguarda ante el poder de la iglesia. Quizá esto corresponda a afirmar que la literatura se halla blindada ante la censura de mejor modo que la filosofía misma.

Volviendo al Diálogo, si se indica que se trata de un escrito meramente filosófico, se desconocería de inmediato una amplia serie de elementos y recursos literarios que ayudan, incluso, a sostener las tesis filosóficas presentadas por el autor a lo largo de las intervenciones de cada uno de los personajes. Por nuestra parte, adoptaremos a lo largo de este escrito una posición contraria a las interpretaciones expuestas en las líneas precedentes y, quizá, también, muy a contravía de la obra cartesiana, meditaremos de mano del contenido literario y filosófico del diálogo, retomaremos, para intentar hacer comprensibles, posiciones resueltamente antagónicas con la intención de establecer algunos aspectos centrales concernientes a la interpretación del texto considerado en su conjunto que nos permitirá, luego de tal análisis, postularlo como la obra fundamental de Descartes. Con todo, la interpretación aquí presentada luchará contra la lectura habitual que postula al Discurso del Método como la obra fundamental de Descartes. También deberá combatir contra posiciones específicas, como la de Koyré, para quien “[...] la gran obra de Descartes debía llamarse El Mundo o Tratado de la Luz [...]" (Koyré, 1980 , p. 68).

\section{El Diálogo}

Mirado en su estructura, el texto cartesiano que lleva por título La Búsqueda de la Verdad Mediante la Luz Natural está dividido en tres partes: un breve epígrafe, una introducción y, finalmente, el diálogo dramático en cuanto tal. En lo que sigue, intentaremos proporcionar, en una exposición separada de cada una de sus partes, algunas indicaciones tanto del propósito de cada una de ellas como de su conjunción en la totalidad del texto.

\section{a. El Epígrafe}

Ya en el epígrafe vemos de modo claro que la finalidad del texto se centra en determinar cuáles son las opiniones que debe tener una persona para ser considerado un hombre íntegro (Cf., 1999, p. 103). Pues bien, tales opiniones son cualificadas por el autor como puras; por ello, hace a un lado tanto la religión como la historia de la filosofía (Cf., 1999, p. 103). Pero este proceder no quiere decir, en modo alguno, que se trate de una mera doxología sin ningún apoyo, todo lo contrario, lo que el autor indica es que las opiniones así concebidas cuentan con una base de la que carece la historia de la filosofía: la razón o el buen sentido que es a lo que corresponde la expresión ‘luz natural' del título del Diálogo. La crítica no consiste tan sólo en afirmar que las opiniones de un hombre íntegro se postulan de un modo puro, sin el apoyo de la filosofía ni de la religión. No, la crítica estriba en el término utilizado por Descartes, la opinión. A primera vista, parece que Descartes retoma eso que la filosofía ha pretendido expulsar desde sus orígenes. Pero al observar las cosas con mayor rigor notamos que la opinión postulada se halla 
cualificada con el adjetivo recta. Así las cosas no se trata, entonces, de la misma doxa que ha sido rechazada de la filosofía, sino de una resemantización del vocablo, lograda gracias al sustento que adquiere de la aplicación de la razón, para postularlo del mismo modo que su filosofía, es decir, como algo absolutamente nuevo.

Las opiniones que deben estar en posesión del hombre íntegro parecen estar dirigidas no sólo a una gran cantidad de contenidos, sino, también, a su profundización. En efecto, el autor afirma que las opiniones del hombre íntegro son todas aquellas que están dirigidas a ocupar su pensamiento y que, además, tienen la facultad de penetrar hasta lo más profundo de los secretos de cada una de las disciplinas del saber (Cf., 1999, p. 103). Hasta este punto da la impresión de que el autor dirige su esfuerzo a todo aquello que pueda ser pensado. Pero no es así, toda vez que Descartes realiza una enumeración taxativa de las ciencias. Esta enumeración, que en los Principia se vale de la famosa metáfora del árbol de la ciencia limita de modo considerable los campos del saber que adquieren la cualificación de ciencia (Cf., 1989, p. 22). Esta delimitación constituye, para el autor, un progreso no sólo porque se ocupa de lo estrictamente científico, sino porque asegura grandes avances en el desarrollo de cada una de las ciencias. Una vez consignado lo anterior, el autor presenta la introducción al diálogo.

\section{b. La Introducción}

La introducción presentada por Descartes tiene por objeto llevar a cabo una profundización de lo planteado en el epígrafe. En ese orden de ideas, el autor dedica unas líneas a hacer algunas precisiones sobre aquello que no requiere la persona que está en formación para ser considerada como íntegra. Esta directriz cuenta con una doble finalidad. En primer lugar, de lo que se trata es de producir tranquilidad en los hombres. Así, para ser un hombre íntegro no se requiere haber leído todos los libros ni saber absolutamente todas las teorizaciones realizadas sobre las diversas materias y objetos de conocimiento. En suma, lo que el autor nos indica es que la calidad de hombre íntegro no es un imposible, se encuentra al alcance de la mano. En segundo lugar, y unida a la anterior observación, el hombre íntegro es aquel que es capaz de alinear sus opiniones a la férula de la razón. En ese sentido, tal y como lo indica el autor, de nada le serviría al hombre que pretenda saberse a sí mismo como íntegro, el haber leído todos los textos, puesto que sólo requiere servirse del instrumento de la razón que está ausente en casi todas las reflexiones y, donde aparece, se deja ver únicamente en apartados y escasos lugares. Pero la razón más importante para renunciar a la lectura de los libros la hallamos en las Reglas, ya que sólo se puede adquirir la ciencia en una profunda investigación de la verdad mediante el ejercicio de intuir de modo claro y distinto, y no mediante la indagación de lo que otros dijeron sobre un punto específico (Cf., 1984, p. 72). Por ello, la lectura de todos los textos constituirá más bien un retroceso que un progreso (Cf., Descartes, 1999, p. 103)².

Seguidamente, y conforme a la indicación realizada en el epígrafe, el autor enfatiza que en esta obra se propone enseñar lo necesario para que un hombre pueda ser considerado íntegro (Cf., 1999, p. 103). El camino para lograr tal propósito no es otro que El Método. Aquí debemos entender un doble sentido del método. En primer lugar, se hace una referencia a las prescripciones indicadas y descritas por el autor en la Segunda Parte del Discurso. En segundo lugar, se hace una referencia específica a la duda como método ${ }^{3}$ que permite derribar todas las concepciones de la historia de la filosofía -y de la historia de la ciencia y de todo tipo de saber hasta entonces conocidos- y conducir al intérprete de modo fiable y seguro a los principios de la metafísica (Cf., 1999, p. 
124), fundamento del verdadero establecimiento de las ciencias.

La duda nos lleva, como decíamos, sobre el camino firme y seguro de la ciencia, es decir, en posesión de un conocimiento cierto y evidente (Cf., Descartes, 1984, p. 66). El acceso a la ciencia, que es posible solo a través de la intuición y de la deducción, en cuanto acciones específicas del entendimiento, es justo lo que encontramos en el diálogo cartesiano (Cf., Descartes, 1984, p. 75). Así, con la duda nos hallamos frente a los principios de la metafísica, a los que se llega por intuición como verdades puras que no requieren de ningún conocimiento anterior. Pero, por otro lado, el progreso que constituye la formulación de los principios de la metafísica se convierte en un prerrequisito para lograr el avance en las ciencias, ya que los primeros principios se erigen como causas tanto de los principios de la física como del posterior desarrollo de las ciencias particulares o filosofías prácticas, a las que se accede por medio de la deducción. Una vez observado lo indicado por el autor tanto en el epígrafe como en la introducción al diálogo, detengámonos, brevemente, en cada una de los personajes que intervienen en la obra.

\section{c. Poliandro, Epistemón, Eudoxio}

Tal y como se indica en el título de este apartado, que corresponde al título propuesto por el autor, se trata de un diálogo establecido entre tres personajes cuyos nombres son: Poliandro, Epistemón y Eudoxio. Si acudimos a la etimología podemos constatar el significado de cada uno de los nombres. Así, Poliandro corresponde a la expresión muchos hombres; Epistemón, el hombre de ciencia y, finalmente, Eudoxio, el hombre de recta opinión. Esta caracterización nos permite constatar que las opiniones ofrecidas por cada uno de los tres personajes quedan absolutamente demarcadas por la semántica de sus nombres. Justo aquí comprendemos el carácter universal tan- to del diálogo como de su propósito. El texto resulta universal porque en él intervienen tres personajes que puede ser cualquier hombre del mundo. En efecto, en él se sentirán identificados quienes desconocen la tradición filosófica, los que la han estudiado $y$, finalmente, los que la han desechado para adoptar la recta opinión. Unido a lo anterior, el diálogo es igualmen"...I para esto no he encontrado estilo más cómodo que el de estas discretas conversaciones en donde cada cual descubre

familiarmente en sus amigos lo mejor de su pensamiento [...]" (Descartes, 1999, p. 106). te universal en la medida en que postula como propósito ofrecer un camino a todos los hombres para que dirijan sus esfuerzos tendientes a establecer una ciencia durable que garantice avances continuos.

Esta condición del diálogo nos ubica de modo certero frente al propósito que el autor le adscribe no sólo a esta pieza literario-filosófica, sino a toda su filosofía. En efecto, se trata de hacer que las conceptualizaciones expresadas se hagan útiles, por ello, Descartes nos dice:

“[...] para esto no he encontrado estilo más cómodo que el de estas discretas conversaciones en donde cada cual descubre familiarmente en sus amigos lo mejor de su pensamiento [...]" (Descartes, 1999, p. 106).

Este propósito se recoge una vez más en los Principia, allí Descartes indica que la utilidad de su filosofía no es distinta a la de llevar a cabo una explicación del orden que debe seguir todo hombre para instruirse (Cf. 1989, p. 21). Y tanto la utilidad como el orden para instruirse se hallan plenamente determinados por la 
verdad como horizonte de la teorización cartesiana.

Como vemos, la presentación de las tesis de Descartes en una forma de composición literaria requiere no sólo una agudeza de los planteamientos, sino que, además, se hace necesario llevar a cabo una serie de artilugios para presentar cada una de las formulaciones. Estos mecanismos literarios parten desde la misma caracterización de los personajes que se expresa en la indicación de sus nombres. Para seguir adelante con el examen del texto propuesto, conviene indicar, a manera de hipótesis, las posibles motivaciones del autor al presentar su reflexión filosófica a partir de una composición literaria.

\section{Tres Hipótesis sobre la Composición del Diálogo}

En lo que sigue apuntaremos tres posibles hipótesis sobre la intención de Descartes al presentar un texto filosófico compuesto a modo de diálogo. Conviene advertir que, consideradas conjuntamente, difícilmente podría afirmarse que las hipótesis resultan excluyentes. De este modo, creemos que una conjunción de las tres ayudaría a una mejor comprensión de la obra cartesiana sometida a estudio.

\section{a. La Popularización de la Filosofía}

El párrafo introductorio al Discurso nos indica que en la Primera Parte se realizará algunas consideraciones relacionadas con las ciencias (Cf., 1981, AT, VI, p. 1). Ya en el desarrollo de la Primera Parte, encontramos que una de esas consideraciones o cuestiones es, precisamente, el tema central y el hilo conductor del diálogo sometido a estudio, es decir, el buen sentido (bona mens) o, más precisamente, la razón, la luz natural. Pues bien, en el Discurso, la razón se nos presenta como aquello que está mejor repartido en el mundo (Cf., 1981, AT, VI, p. 1). De esta afirmación se hace pertinente subra- yar, por lo menos, primariamente, dos conclusiones. En primer lugar, que esa igualdad de la razón en cada uno de los miembros de la especie humana corresponde a una disposición de la naturaleza. De este modo, la razón se convierte en el primer derecho innato del hombre. Así, por ejemplo, antes de ser ciudadano de tal o cual país, se es poseedor de razón por el hecho mismo de nacer 0 , al completar la metáfora de los derechos, podríamos decir que al nacer nos hacemos ciudadanos de una patria superior y anterior a todas, la razón. Junto a esta primera conclusión, encontramos, en segundo lugar, la principal característica adscrita a la razón, la posibilidad de llevar a cabo la distinción entre lo verdadero y lo falso ${ }^{4}$. Puesto de relieve lo anterior, desembocamos, entonces, en el centro mismo de la orientación de la investigación cartesiana, pues recordemos que el esfuerzo de este filósofo está dirigido hacia la búsqueda y establecimiento de la verdad. Y el prerrequisito de tal resultado lo constituye la posibilidad de discernir lo verdadero de lo falso, es decir, lo resaltado en la segunda conclusión que constituye, ni más ni menos, la primera de las reglas para la dirección del espíritu (Cf., Descartes, 1984 , p. 61). Siguiendo el camino trazado por las indicaciones dadas, podemos afirmar, desde este punto de vista, que la labor filosófica (entendida como una investigación de la verdad) puede ser llevada a cabo por cualquier ser humano (Cf., Descartes, 1981, AT, VI, p. 72). ${ }^{5}$

En el referido párrafo introductorio al Discurso, Descartes indica que la temática desarrollada en la sexta parte se extiende sobre dos ejes fundamentales. En el primero, se apuntará lo necesario para llevar a cabo un avance significativo en la investigación de la naturaleza. El segundo eje resulta sumamente interesante tanto para la composición del texto como para la hipótesis que intentamos demostrar; pues desde una posición autobiográfica el autor expondrá las razones que lo lle- 
varon a escribir sus textos (Cf., Descartes, 1981, AT, VI, p. 72). Para la hipótesis del diálogo como intento de popularización de la filosofía cartesiana, incluimos como punta de lanza de la argumentación, la posición revolucionaria de Descartes al abandonar el latín como lengua de expresión del pensamiento filosófico. El escribir en lengua vernácula se convierte en una fuerte contestación a la época medieval y al predominio de la Iglesia en la interpretación de los textos. Pero la razón aducida por Descartes para escribir en francés hace conexión con lo apuntado líneas arriba sobre la primera parte del Discurso, es decir, al buen sentido como carta de ciudadanía. Descartes lo expone del siguiente modo:

[...] Y si escribo en francés, lengua de mi país, y no en latín, la lengua de mis preceptores, es porque espero que aquellos que solamente se sirven de su razón natural, carente de todo prejuicio, juzgarán más correctamente mis opiniones que aquellos que no aceptan sino el pensamiento antiguo [...] (Descartes, 1981, AT, VI, p. 72).

Como se ve, el autor fundamenta el desarrollo de la filosofía, o, lo que es lo mismo, el avance de las ciencias, en ese derecho humano innato, la razón. Además, la cita nos pone frente a uno de los principios de la modernidad, el intento de eliminar de toda clase de prejuicios, y ello sólo es posible mediante el ejercicio constante de la razón.

Vistas las cosas desde la conjunción propuesta de la primera y sexta partes del Discurso y, mejor aún, desde la totalidad del texto, la popularización de la filosofía se destaca a tal punto que se convierte casi en un pleonasmo, pues la pretendida divulgación indicada en el diálogo tiene como carta de derechos una popularización anterior que es obra de la naturaleza, la de la razón. Y justamente en el nodo de la razón se centra la fuerte crítica que Descartes realiza a la tradición, en la medida en que la considera carente de verdad, como lo demuestra la siguiente hipótesis.

\section{b. El Debate con la Tradición}

Recordemos que en el diálogo intervienen tres personajes claramente determinados: Poliandro, Epistemón y Eudoxio. El talento dramático de Descartes, para parafrasear a Borges, se expresa en la obligación de hacer hablar a sus personajes. Para
Puesto que me llamáis

a participar en la conversación e incluso me incitáis a ello, voy a mostraros lo que vale una lógica irritada y a la vez crearos tales dificultades $y$ obstáculos que no sólo Poliandro, sino vos mismo, difícilmente podréis resolver [...] (Descartes, 1999, p.

130). ello, procede a circunscribir las opiniones de cada uno de ellos en el ámbito demarcado por la etimología de cada uno de sus nombres.

Vistas así las cosas, el terreno para el debate está más que abonado. El hombre que posee la recta opinión (Eudoxio) reta a la tradición filosófica encarnada en Epistemón, a quien finalmente vence. Esta lectura general parece contener una incomodidad especial, la presencia de Poliandro. Pues desde la totalidad del diálogo resulta difícil establecer el rol que cumpliría Poliandro en este debate. Pero si se acude a la especificidad de los parlamentos, nos es mucho más cómodo indicar tanto la presencia del debate entre Eudoxio y Epistemón como el papel cumplido por Poliandro en el certamen. Antes que nada, se hace necesario indicar que el debate es propiciado por Eudoxio. Lo anterior se puede constatar en las palabras que Epistemón le dirige: 
Puesto que me llamáis a participar en la conversación e incluso me incitáis a ello, voy a mostraros lo que vale una lógica irritada y a la vez crearos tales dificultades y obstáculos que no sólo Poliandro, sino vos mismo, difícilmente podréis resolver [...] (Descartes, 1999, p. 130).

Esta observación nos deja ver claramente que de lo que se trata es de un debate, y las palabras de Epistemón constituyen el prólogo mismo si no de la discusión, por lo menos, sí de la aceptación del debate.

Ante las duras palabras de Epistemón, Eudoxio acaba por sellar el pacto, pero con una condición dirigida a Poliandro:

“Con gusto, esta vez me encargo de ello, pero con la condición de que seáis juez de nuestra discusión [...]" (Descartes, 1999, p. 130).

De lo citado conviene resaltar, por lo menos, tres indicaciones. En primer lugar, nótese que el pacto se cierra luego de un tránsito, las palabras de Epistemón hacen eco en Poliandro, quien no tiene más remedio que ceder el lugar a Eudoxio, toda vez que se halla incapacitado para el debate. En segundo lugar, Eudoxio postula a Poliandro como juez de la discusión, pero esta calidad que Poliandro recibe de las palabras de Eudoxio ya existe en la persona de Poliandro, quien, gracias al tránsito que apuntábamos anteriormente, lo que hace es dar parte a Eudoxio para que responda a los fuertes cuestionamientos de Epistemón. En este sentido, Poliandro no se constituye en juez por las palabras de Eudoxio, lo que hace la intervención de éste es confirmar una prerrogativa que se ha dado Poliandro motu proprio. Por último, se hace viable sugerir que esta remarcación de Poliandro como juez repercute en la estructura de debate que le adscribimos al texto en estudio. Pero este debate requiere de un fallo tanto interior como exterior. Del interior, la sentencia del juez Poliandro favorece ampliamente a las pretensiones de Eudoxio y, por tanto, de la filosofía cartesiana. EI juicio externo requiere del mis"Con gusto, esta vez me encargo de ello, pero con la condición de que seáis juez de nuestra discusión [...]" (Descartes, 1999, p. 130).

ya en la persona de Poliandro, sino en su contenido etimológico. El fallo es, pues, tarea de los muchos hombres que se enfrenten a la lectura del diálogo. A cada uno de ellos le corresponde indicar si la victoria pertenece a Eudoxio o a Epistemón.

El avasallante triunfo de la recta opinión guiada por la luz natural de la razón en el diálogo, parece obedecer, en última instancia, a una prerrogativa propedéutica dirigida a establecer el uso de la razón como único prerrequisito de la instauración y perennidad de las ciencias. Esta postulación de la razón exige, como es apenas natural, el inmediato rechazo de la tradición, ya que es calificada en todo momento como verosímil y, por ello mismo, insistamos, como carente de los dictados de la razón. Pero el resultado del debate no nos indica únicamente lo anterior. La victoria de Eudoxio y, por tanto, de la filosofía cartesiana exige, de igual modo, un reconocimiento del campo de batalla en que se ha librado el combate, el diálogo. Al examinar lo anterior, nos es lícito juntar a esta suposición la primera de las hipótesis apuntadas, la popularización de la filosofía, pero enseñada aquí como divulgación tanto del debate como del triunfo de Eudoxio. Sin embargo, la total conjunción de las hipótesis la hallamos al indicar que la verdad sólo puede ser fruto del diálogo, tal y como se expone en la tercera de las hipótesis. 
c. La Verdad como Propósito y Resultado de la Conversación

La forma de conversación que adquiere el diálogo nos pone frente a lo más idóneo para la consecución de la verdad. Lo anterior se muestra claramente en los continuos parlamentos entre Eudoxio y Poliandro, toda vez que éste logra llegar a la verdad y postularse, incluso, como maestro de Epistemón. Pero la confirmación de esta hipótesis se encuentra en la correspondencia entre Descartes y Arnauld fechada entre los meses de junio y julio de 1648 (Cf., Descartes, 1997, p. 183). Observemos, pues, estas cartas a la luz de lo indicado.

La correspondencia inicia con una extensa carta que Arnauld (como se sabe, las cartas no se dirigían directamente a Descartes, sino a su editor y éste tenía el encargo de hacerlas llegar al filósofo) en la que se le presenta a Descartes una serie de dudas sobre ciertos planteamientos expuestos a lo largo de sus textos (Cf. Descartes, 1981, AT, VI, p. 75). De la mencionada carta, llamaremos la atención sobre las palabras utilizadas por Arnauld en el saludo. Las palabras son las siguientes: "llustrísimo varón: No quisiera perturbar con discusiones tu ocupadísimo ocio [...]" (Descartes, 1997, p. 189). La intención de Arnauld resulta totalmente clara, él no quiere perturbar a Descartes en su descanso, pero las incomodidades que tiene respecto a algunos tópicos, le llevan a dirigir la carta al filósofo para que éste dé respuesta a sus inquietudes. En este orden de ideas, el propósito de la carta es realizar una petición de aclaración de algunas cuestiones. La relación que postula la carta es idéntica a la establecida entre Eudoxio y Poliandro, es decir, la de maestro-alumno. Arnauld se ha hecho alumno de Descartes en la lectura de sus textos. Y, en consecuencia, dirige una misiva a su maestro con el objeto de que le solucione ciertas dudas frente a las que se siente impotente. En resumidas cuentas, el alumno pregunta al maestro.

La respuesta de Descartes a las incomodidades de Arnauld se hace muy breve. A pesar de ello, sienta las bases en las que se sustenta esta tercera hipótesis. Así, en la in"Ciertamente decís cosas extraordinarias y lo hacéis con tal excelencia que yo mismo no podría hacerlo mejor [...]" (Descartes, 1999, p. 106). troducción de la carta leemos:

Aunque el autor de las objeciones que me entregaron ayer no ha querido ser conocido ni de nombre ni de cara, lo mejor que tiene, a saber, el ingenio, no ha podido ocultarlo. Y como veo que se trata de un hombre muy perspicaz y docto, no me avergonzaré de que me supere y me enseñe. Pero como declara que no se dedica a disputar sino únicamente a descubrir la verdad, responderé aquí brevemente y dejaré algo para una conversación; pues pienso que es más prudente tratar por escrito con los disputadores, pero que con los que buscan la verdad es preferible hacerlo de viva voz (Descartes, 1997, p. 197).

Como se ve, este párrafo introductorio a la carta está dividido en tres partes. En la primera de ellas se hace un elogio del interlocutor. En la segunda parte declara que gracias a la calidad del destinatario no se sentiría avergonzado si este hombre le supera, y no titubea ni un solo instante al afirmar que bien podría invertir la relación que Arnauld le planteó en la primera carta. De este modo, el alumno sería ahora Descartes. La misma inversión de la relación la hallamos en el diálogo entre Eudoxio y Poliandro. Allí, ante los progresos de Poliandro, Eudoxio le indica lo siguiente:

“Ciertamente decís cosas extraordinarias y lo hacéis con tal excelencia que 
yo mismo no podría hacerlo mejor [...]" (Descartes, 1999, p. 106).

Como se ve, ante lo bien dispuesta que demuestra estar la razón en Poliandro, Eudoxio no duda ni un instante en afirmar que lo ha superado, que ahora es mejor que el maestro, pues ve en lo concluido tal claridad que dice no poder afirmarlo de mejor modo. Poliandro acaba por ser, también, el maestro de Epistemón, hecho que se puede calificar como la más dura de las burlas a la historia de la filosofía. La tercera parte nos sitúa en los ámbitos de la conversación y la discusión. De este modo, si dos o más están empeñados en buscar la verdad deben unirse mediante la conversación, pero si su propósito es la discusión, entonces deben preferir comunicaciones escritas.

No obstante lo dispuesto en la correspondencia sobre el pasar al plano de la conversación, ésta continúa porque Arnauld utiliza como coartada, para mantenerse en secreto, el estar a gran distancia del filósofo. En consecuencia, en la posterior carta afirma lo siguiente:

Ilustrísimo varón: No dudo de que sería mucho más fácil tratar estas cuestiones en una conversación que por escrito [...] En efecto, tu respuesta, aunque muy breve, me ha ayudado mucho a entender cosas muy difíciles, y me ha hecho concebir la esperanza de que entre personas que no están en el mismo lugar es posible establecer un diálogo en el que, lejos de todo afán de disputa (que entiendo que tú aborreces tanto como yo), se busque solamente la verdad con una buena fe filosófica o más bien cristiana (Descartes, 1997, p. 201).

Si llevamos a cabo una comparación de la primera misiva de Arnauld con ésta encontramos básicamente la misma forma. En efecto, la introducción en ambas es igual; las dos se dirigen a Descartes como varón ilustre. A simple vista, esto no pareciera indicar nada distinto al modo común y ordinario de encabezar una carta, es decir, de realizar el saludo al destinatario. Pero a partir de ahí se dejan ver todos los niveles de relación que teje la carta. Nos referimos, propiamente, a la relación alumno-maestro. Esta relación se empezó a labrar en la lectura de los textos cartesianos y se hizo explícita en la primera de las cartas. Pero Descartes, atormentado por la sapiencia de su alumno, no dudó ni un instante en postularlo como maestro. Y quizá sea ésta la única objeción que se presenta en la correspondencia. Arnauld se niega a ello, no se cree con las fuerzas suficientes para ser el maestro de Descartes. Es más, no pierde oportunidad para recordar que el maestro es el filósofo y no él. Por ello, afirma que la breve respuesta le ha ayudado mucho.

La segunda parte de la cita es una reiteración de lo establecido en la anterior misiva sobre la conversación y la disputa. Se trata, entonces, de confirmar que tanto Arnauld como Descartes están empeñados en el proyecto cartesiano, es decir, en buscar la verdad. Este propósito común los lleva a aborrecer la disputa, pues ésta se perfila como un sin sentido en la medida en que interrumpe tanto el avance constante como el establecimiento de la verdad a que debe estar sometida la ciencia. La disputa con los defensores de la tradición se hace más que incómoda y, por ello mismo, constituye una obligación tomar distancia mediante la utilización del texto escrito. La conversación, por su parte, cuenta con la finalidad de "[...] establecer alguna vez algo firme y permanente en las ciencias" (Descartes, 1997, p. 15).

De este modo, el propósito expresado por Descartes al inicio de las Meditaciones se convierte en el propósito general de la filosofía. En este sentido, el diálogo más que la filosofía, se postula como su garantía. 


\section{A manera de conclusión}

Desde una panorámica de la historia de la filosofía, la directriz de la verdad como propósito y efecto de la conversación, nos lleva al origen mismo de la filosofía, al diálogo platónico, pero como Descartes lo ha rechazado por no encontrar en él la verdad, sino un injustificado uso de la duda que lo conduce a la aporía, tal direccionamiento se hace insostenible ${ }^{6}$. Desde la perspectiva del pensamiento radical cartesiano como fundador de la filosofía, como creador de un pensamiento absolutamente nuevo que tiene por objeto la verdad, La Búsqueda de la Verdad Mediante la Luz Natural se postula como el primer diálogo de la historia de la filosofía y, quizá, como el primer texto auténticamente filosófico, en la medida en que está orientado hacia el propósito general de la obra de Descartes indicado en las Meditaciones, es decir, el de "[...] establecer alguna vez algo firme y permanente en las ciencias" (Descartes, 1997, p. 15).

El diálogo se erige, entonces, como texto filosófico desde dos cimientos. El primero de ellos es la verdad. Para la consecución de la verdad no es suficiente sentarse a dialogar y tener como propósito su búsqueda. Se requiere algo más: el método. Así las cosas, como el mismo autor nos lo recuerda en las Reglas, resulta "[...] mucho más acertado no pensar jamás en buscar la verdad de las cosas que hacerlo sin método [...]" (Descartes, 1984, p. 79). $Y$ el método no es otro que el expuesto por Descartes. De este modo, la conversación encuentra su ideal complemento para desembocar en la verdad. Los personajes que hemos relacionado, tanto los reales como los propuestos desde la ficción, son plenamente conscientes de la necesidad del método. Así, Arnauld, que ha leído a cabalidad la obra cartesiana y que, además, manifiesta su total acuerdo con ella, da plena fe de la verdad como resultado tanto del establecimiento como de la práctica del método. Poliandro, por su parte, conducido por Eudoxio, reconoce los grandes progresos a que le lleva el mantenerse fiel a los lineamientos del método.

Al observar el carácter genérico del texto, constamos la conjunción de las tres hipótesis propuestas. En efecto, el diálogo es escrito originalmente en francés, acude a la razón como pauta para indicar la veracidad de lo consignado; por otro lado, reafirma su carácter de confrontación con la tradición, además, por último, finca la conversación como mecanismo idóneo de conducción hacia la verdad. Con base en ello, La Búsqueda de la Verdad Mediante la Luz Natural se perfila como la obra filosófica por antonomasia, en la medida en que conjuga los dos apuntes que conducen a la verdad, la conversación ${ }^{7}$ y el método. Vistas así las cosas, el diálogo cartesiano deja de ser una curiosidad o, cuando mucho, una forma de expresión a la vez literaria y filosófica para postularse como la gran obra de la filosofía cartesiana o, cuando menos, la que cumpliría a cabalidad con los postulados y tesis de la verdad como horizonte de investigación ${ }^{8}$.

\section{Notas aclaratorias}

${ }^{1}$ Cuando hablamos del último Descartes nos referimos a las obras posteriores a El Mundo. Tratado de la Luz, según la clasificación presentada por Turró. (Cf., Turró, 1985, p. 366 ss).

2 En este punto, podría indicarse que Descartes se convierte en un fuerte antecedente de Schopenhauer, pues recuérdese que el filósofo pesimista indica la importancia de no llevar a cabo la lectura de todos los libros como la mejor vía para instruirse, ya que junto con los libros, indica el filósofo alemán, no se vende el tiempo requerido para llevar a cabo su lectura. De este modo, los dos filósofos, desde perspectivas abiertamente distin- 
tas, coinciden en lo perjudicial que resulta la lectura de gran cantidad de libros.

${ }^{3}$ Hablamos de la duda como método siguiendo las reflexiones de Gómez Giraldo, quien indica que al interior de la duda es posible constatar dos reglas metodológicas: la regla de economía y la regla de garantía o control. La regla de economía indica la pertinencia del ataque a los principios del conocimiento y no a los contenidos particulares, tal y como obra Descartes en la Primera Meditación. La regla de garantía o control exige el rechazo de todo contenido sobre el que sea posible predicar la duda. (Cf., Gómez, 2002, p. 17).

${ }^{4}$ Para Arango, la formulación presentada constituye una ironía en la tematización de Descartes, toda vez que el filósofo francés la postula como algo repartido equitativamente por la naturaleza, mientras que, por otra parte, todo el proyecto cartesiano consiste en redefinir el juicio y, a partir de ello, llevar a cabo la distinción entre lo verdadero y lo falso (Cf. 2002, p. 170).

${ }^{5}$ La invitación que realiza Descartes a sus congéneres para que contribuyan con el progreso y avance de la ciencia puede ser entendida como una muestra de pedantería por parte del autor, pues establece en su cabeza el origen de la filosofía al postular y desarrollar los principios de la metafísica, con lo que se deja para los demás la continuación de la empresa, es decir, el desarrollo de las ciencias particulares. Pero lo que realmente parece indicar este pasaje es la fe en la razón como único instrumento con el que se cuenta para llevar a cabo el avance en la ciencia. Por otra parte, y seguida la metáfora de los derechos presentada líneas arriba, bien se podría indicar que este pasaje resulta abiertamente incendiario, toda vez que parece entronizar la posibilidad de la construcción si no social, por lo menos sí democrática del conocimiento.
${ }^{6}$ Con todo, conviene apuntar que en el Protágoras, Sócrates se niega a participar de la discusión con Protágoras, toda vez que no ve en él a un hombre que se atenga a la verdad, sino a un hacedor de discursos que, por ello mismo, se niega a realizar una búsqueda de la verdad mediante la formulación de preguntas y respuestas breves, es decir, ve en el sofista a un hombre que no acude a la conversación como vía idónea para llegar a la verdad. La repulsión producida en Sócrates se hace tan fuerte que se levanta con la plena intención de abandonar el recinto. Y lo hubiese hecho, de no ser porque Calias interviene, haciéndole quedar mediante la utilización de la fuerza. La comparación entre estos textos exigiría todo un desarrollo que aquí nos es imposible acometer. Por ello, sólo indicaremos que, además de lo señalado sobre la conversación, tal trabajo abarcaría el examen de las siguientes puntualizaciones: la elaboración del Protágoras, su carácter de debate y su finalidad educativa. En lo atinente a la elaboración del diálogo platónico, habría que especificarse que la tradición lo fecha como el primero. Quizá lo anterior haga que el texto esté más sujeto a los dictámenes de Sócrates. En ese sentido, la dura crítica de Descartes, según la cual, Platón tuerce completamente las enseñanzas de Sócrates para presentar lo verosímil como si fuese verdadero, parece desdibujarse un tanto. Por otra parte, el texto es un enfrentamiento entre dos hombres: Protágoras, exponente de la tradición sofística, y Sócrates, quien intenta proponer un nuevo modelo de razonamiento como medio para llegar a la verdad. El carácter de certamen es remarcado por Hipias, quien insiste en la necesidad de que se establezca un juez, con el objeto de que, al final, profiera una decisión. Pero Sócrates, que no llega a establecer en cabeza de todos los hombres la calidad de buen sentido como medio para distinguir lo 
verdadero de lo falso, demarca la imposibilidad de postular un juez de entre los presentes, porque de tal hecho surgirían las siguientes ejemplificaciones. En primer lugar, se correría el riesgo de elegir a uno menos sabio que ellos, por lo que su veredicto quedaría viciado; en segundo lugar, resultaría imposible elegir a uno más sabio, ya que, advierte Sócrates, no hay otro más sabio que Protágoras, y, finalmente, indica Sócrates, si eligieran a uno igual de sabio a ellos, la actuación del pretendido juez se haría idéntica a la de los enfrentados en el certamen, de tal modo que la designación se haría inútil. En este punto, las palabras de Sócrates deben ser leídas desde la misma negativa a participar de la búsqueda de la verdad mediante discursos, pues éstos son los que requieren de jueces y de dictámenes. La conversación, por su parte, estaría ajustada a la criba de la razón y, por ello mismo, no requiere otro juez que la misma razón. La finalidad educativa del texto se constata en dos niveles: en la situación misma del enfrentamiento y en la totalidad del diálogo, visto desde su finalidad. El primero se hace patente mediante una clasificación de los asistentes a la conversación. En efecto, en ella encontramos, básicamente, tres grupos de personas: unos, inclinados hacia Protágoras; otros hacia Sócrates, $y$, también, un tercer grupo, como nos lo recuerda Critias, con el propósito de hacerse a las enseñanzas que surjan de la conversación entre Protágoras y Sócrates. Por otra parte, el carácter educativo del texto platónico se hace explícito desde la finalidad misma del diálogo, pues la conversación tiene por objeto establecer si la virtud puede o no ser enseñada. (Cf., Platón, 2006, 335a ss).

${ }^{7}$ Finalmente, se hace necesario indicar que la construcción de la hipótesis de la conversación encuentra en Gadamer una dura objeción. Toda vez que para este filósofo, en cuanto más auténtica es la conversación, se hace imposible dirigirla hacia un objetivo específico. Apuntado lo anterior, las tesis cartesianas sobre la verdad como resultado de una conversación fracasarían completamente. Sin embargo, apoyados en el mismo Gadamer se podría revitalizar la tesis en la medida en que para este autor, la conversación es entendida como un proceso que busca llegar a algo. $Y$ ese algo que busca con Descartes y, específicamente, en el diálogo estudiado sería la verdad. (Cf., Gadamer, 1996, p. 461 y ss.).

${ }^{8}$ Es importante tener en cuenta que la conclusión a que hemos llegado luego del análisis de los tres aspectos mencionados no es absolutamente nueva en la comprensión de la filosofía cartesiana. Así, Ortega y Gasset, por ejemplo, en la tercera de sus conferencias de Lisboa de 1944, aunque no formula expresamente la conclusión que hemos propuesto, sí da un par de indicaciones al respecto. En esta conferencia, el filósofo español se encarga de realizar un recuento de las principales contribuciones de la filosofía y constata que todas ellas están mediadas por un estilo absolutamente literario. A ello corresponde la metafísica de Parménides, formulada en un poema; el diálogo platónico, portador, dice Ortega, de alta poesía; los diálogos aristotélicos, de los que, dice, por desgracia sólo se conservan fragmentos $y$, finalmente, Descartes que realiza su máxima contribución a partir del Discurso y del diálogo objeto de estudio en este capítulo. Lo anterior faculta a Ortega para afirmar en una nota a pie de página: "Porque es preciso decir que nunca, jamás ha venido nada creador, importante y nuevo a la Filosofía en un libro o discurso que tenga el estilo del Manual, Handbuch, Vademecum o de una lección soporífera dada a colegiales [...]." (Ortega, 1997, p. 274) Como se ve, Ortega no llega a afirmar, específi- 
camente, que este diálogo sea la obra fundamental de Descartes, entre otras cosas, por el hecho de que haya quedado inconcluso, pero sí indica, como veíamos, que el estilo literario marca siempre la posibilidad de decir algo verdaderamente nuevo, radical $y$, por ello mismo, de mérito en filosofía.

\section{Referencias}

DESCARTES, R. (1981). Discurso del Método, Madrid: Alfaguara.

DESCARTES, R. (1999). La Búsqueda de la Verdad Mediante la Luz Natural, Bogotá: Panamericana.

DESCARTES, R. (1997). Meditaciones Metafísicas y Otros Textos, Madrid: Gredos.

DESCARTES, R. (1984). Reglas para la Dirección del Espíritu, Madrid: Alianza.

DESCARTES, R. (1989). Sobre los Principios de la Filosofía, Madrid: Gredos.

GADAMER, H. (1996). Verdad y Método I, Salamanca: Ediciones Sígueme.

GÓMEZ, A. (2002). Descartes Ayer y Hoy, Cali: AC Editores \& Alego Editores.

KOYRÉ, A. (1980). Estudios de Historia del Pensamiento Científico. México: Siglo XXI Editores.

ORTEGA Y GASSET, J. (1997). Obras Completas, Tomo $X I I$, Madrid: Alianza.

PLATÓN (2006). PROTÁGORAS, Madrid: Alianza.

TURRÓ, S. (1985). Descartes. Del Hermetismo a la Nueva Ciencia, Barcelona: Anthropos. 